OPEN ACCESS

Edited by:

Sara Manti,

University of Catania, Italy

Reviewed by:

Antonio Caputi

University of Bari Aldo Moro, Italy

Yuke Tien Fong

Singapore General Hospital,

Singapore

*Correspondence:

Huimin Guo

g0517@sina.com

Xiaojie Huang

huangxiaojie78@ccmu.edu.cn

tThese authors have contributed equally to this work and share first authorship

Specialty section

This article was submitted to Infectious Diseases - Surveillance,

Prevention and Treatment, a section of the journal

Frontiers in Public Health

Received: 13 October 2021 Accepted: 08 December 2021

Published: 24 January 2022

Citation:

Lian X, Zhang L, Zhao Y, Li Y, Jing X, Liu X, Han J, Ma J, Zhang Y, Guo H and Huang $X$ (2022) Utilization of a Mobile Multifunctional Workstation for Coronavirus

Nasopharyngeal/Oropharyngeal Specimen Collection.

Front. Public Health 9:794359.

doi: 10.3389/fpubh.2021.794359

\section{Utilization of a Mobile Multifunctional Workstation for Coronavirus Nasopharyngeal/Oropharyngeal Specimen Collection}

\author{
Xiaojing Lian ${ }^{1 \dagger}$, Lili Zhang ${ }^{2 \dagger}$, Yang Zhao ${ }^{3 \dagger}$, Yuhua $\mathrm{Li}^{4}$, Xuemin Jing ${ }^{5}$, Xin Liu ${ }^{6}$, Jianing Han ${ }^{7}$, \\ Jianhong $\mathrm{Ma}^{7}$, Yongyong Zhang ${ }^{8}$, Huimin Guo ${ }^{2 *}$ and Xiaojie Huang ${ }^{9 *}$ \\ 1 Integrated Traditional Chinese and Western Medicine Center, Beijing Youan Hospital, Capital Medical University, Beijing, \\ China, ${ }^{2}$ Nursing Department of Beijing Youan Hospital, Capital Medical University, Beijing, China, ${ }^{3}$ Department of \\ Dermatology, Shunyi Maternal and Children's Hospital of Beijing Children's Hospital, Beijing, China, ${ }^{4}$ Second Department of \\ Infection, Beijing Youan Hospital, Capital Medical University, Beijing, China, ${ }^{5}$ Intervention Department, Beijing Youan Hospital, \\ Capital Medical University, Beijing, China, ${ }^{6}$ Department of Critical Care Medicine, Beijing Youan Hospital, Capital Medical \\ University, Beijing, China, ${ }^{7}$ Department of Infection, Beijing Youan Hospital, Capital Medical University, Beijing, China, \\ ${ }^{8}$ Outpatient Department, Beijing Youan Hospital, Capital Medical University, Beijing, China, ${ }^{9}$ Center for Infectious Disease, \\ Beijing Youan Hospital, Capital Medical University, Beijing, China
}

Objectives: This study aimed to explore the utilization of a mobile multifunctional workstation for COVID-19 sample collection.

Methods: Twenty-four nurses and 150 individuals who took nucleic acid tests using mobile multifunctional workstations in Beijing Youan Hospital, Capital Medical University, from September to November 2020, were enrolled in the study as the observation group. As the control group, we included 36 nurses and 150 individuals who did not use the workstations from June to September 2020. We compared the two groups on (1) comfort of working environment, self-perceived security, the convenience of information system, operational process flexibility, pharyngeal acquisition visibility, and effectiveness of communication among nurses; and (2) self-perceived safety, waiting time, and overall satisfaction among individuals who took nucleic acid tests.

Results: The satisfaction score of nurses in the observation group of nurses were significantly higher than those of the control group (OR $=17.29795 \% \mathrm{Cl}: 4.294$, 69.673), as well as the convenience of the information system (OR $=6.25095 \% \mathrm{Cl}$ : $1.775,22.008)$, and communication effectiveness ( $\mathrm{OR}=5.58895 \% \mathrm{Cl}: 1.590,19.646)$. Among individuals who took nucleic acid tests, the overall satisfaction $(P<0.05)$ and self-perceived security $(P<0.05)$ had statistical differences between the observation group and the control group.

Conclusions: The mobile multifunctional workstation for specimen collection could improve the comfort of the working environment, the convenience of information systems, and the effectiveness of communication among nurses.It can improve satisfaction and self-perceived security among people who took nucleic acid tests.

Keywords: mobile multifunctional workstation, satisfaction, COVID-19, specimen collection, nasopharyngeal/oropharyngeal specimen collection 


\section{INTRODUCTION}

The transmission of coronavirus (COVID-19) takes place mainly through respiratory droplets and close contact. If people are exposed to aerosols in a closed environment, it carries an increased infection risk (1). Taking nasopharyngeal swabs for nucleic acid detection has become a convenient screening method (2). When collecting samples, contact with respiratory exhalations or secretions of patients with COVID-19 is a high-risk procedure. Thus, the Guidelines for the Use of Common Personal Protective Equipment in the Prevention and Control of SARS-CoV-2 (3) stipulates that in case of close contact with a patient who has confirmed or suspected COVID-19, collectors must comply with the thirdlevel protection standards to ensure the safety of healthcare workers collecting specimens.

However, complying with third-level protection causes considerable discomfort. In addition, the costs of PPE and the amount of medical waste produced is very high. Moreover, specimen collection, processing, and storage should follow the procedure of early collection, aseptic operation, and cryopreservation (4). However, samples are usually placed at room temperature after collection, which does not meet the sample preservation regulations, thus affecting the test accuracy. The study aimed to explore the application of mobile multifunctional workstations for sample collection.

The workstation is composed of a collection kiosk and a multifunction console. We creatively integrated an information system into the workstation, which solved the current issue of workstations not having information systems. The information system enables nurses to complete registration by scanning QR codes efficiently, and medical staff can easily trace the sample throughout the process. The original workstation generally had a closed negative- or positive-pressure design, with built-in air conditioning. We adopted a closed positive-pressure design and incorporated a fresh air system-the cleanliness reached the ISO6 cleanroom standard. Based on traditional ultraviolet disinfection, automatic disinfection outside the workstation was added. Furthermore, we also added an anti-fog panel, inductive dustbin, constant temperature refrigerator, and other details that improved the practicability and convenience of use of the workstations.

\section{METHODS}

\section{Ethical Approval}

The study was conducted in compliance with the Declaration of Helsinki. All the participants signed informed consent. The studies involving human participants were reviewed and approved by the Ethics Committee of Beijing Youan Hospital Affiliated with the Capital Medical University.

\section{Study Population}

Twenty-four nurses from Beijing Youan Hospital working from September to November 2020 in the screening outpatient department were selected as the observation group. They used the mobile multifunctional sample collection kiosk to collect throat swabs from individuals who took nucleic acid tests. From June to September 2020, 36 nurses from the outside collection team of the nucleic acid testing group served as the control group. They followed third-level protection standards while collecting throat swabs from sampled people outdoors. The selected people were all women. Furthermore, 150 individuals who took nucleic acid tests $\mathrm{s}$ through a collection kiosk from September to November 2020 were selected as the observation group. From June to September 2020, 150 individuals who took nucleic acid tests were selected as the observation group without being collected through the collection kiosk.

The observation group nurses wore nurse uniforms, medicalsurgical masks, and disposable gloves in the collection pavilion. They are equipped with a head-mounted LED light supplement device to perform throat swab sampling. Then, the nurses inserted their hands into the external connection gloves. After disinfection, the sampling tube is delivered from the person sampled to the nurse through the voice interaction system. After sampling, the nurse puts the throat swab into the sampling tube, seals the cap, puts it in the delivery port, and pushes the complete button to finish the sampling process. The test tube racks are placed in a row and placed in the refrigerator. After the operation, the nurse uses the foot-operated spray disinfection system to ensure the disinfection of each individual.

We distributed 60 nurse and 300 subject questionnaires. The content of the nurses' satisfaction evaluation of different work modes included the following six aspects: work environment comfort, self-perceived security, information system convenience, operating process flexibility, pharynx collection visibility, and nurse-patient communication effectiveness. The content of the collected personnel's satisfaction evaluation included the following three aspects: self-perceived security, sampling waiting time, and overall satisfaction. Both questionnaires use a 5-point Likert scale, with "very dissatisfied," "unsatisfied," "average," "satisfied," and "very satisfied" in the order from 1 to 5 .

\section{Statistical Analysis}

We analyzed the count data and normally distributed measurement data using a chi-squared or a Fisher's exact test and $t$-test separately in SPSS 25. In addition, we analyzed non-normally distributed measurement data and ordered count data by a rank-sum test of two independent samples. According to the nurses' feelings of taking nasopharyngeal swab samples, which included comfort of working environment, self-perceived security, the convenience of information system, operational process flexibility, pharyngeal acquisition visibility, and effectiveness of communication, 4-5 points were regarded as satisfaction and 1-3 points were regarded as dissatisfaction. Then the effects of age, years of work, positional titles, educational degree, and method of coronavirus nasopharyngeal/oropharyngeal specimen collection (collected through the collection kiosk or wearing PPE) on the nurses' feelings were analyzed. We carried out bivariate logistic regression analyses in SPSS 25 . Then we selected the factors with a $p$-value $<0.2$ for multivariate analysis. 
TABLE 1 | Comparison of the two groups of nurses with different work patterns.

\begin{tabular}{|c|c|c|c|c|}
\hline Item & $\begin{array}{l}\text { Control group } \\
\qquad(n=36)\end{array}$ & $\begin{array}{l}\text { Observation group } \\
\qquad(n=24)\end{array}$ & Statistics & $P$-value \\
\hline Age & $36.50(33.25-43.50)$ & 36.50 (31.00-43.00) & $Z=-0.280$ & 0.780 \\
\hline Years of work & $16.00(10.00-23.50)$ & $14.50(10.00-24.00)$ & $Z=-0.060$ & 0.952 \\
\hline Positional titles & & & $x^{2}=0.262$ & 0.609 \\
\hline Primary nurses & 16 & 10 & & \\
\hline Supervisor and deputy chief nurse & 20 & 14 & & \\
\hline Education degree junior college education & & & $X^{2}=0.045$ & 0.832 \\
\hline \multirow[t]{2}{*}{ Bachelor degree or above } & 7 & 6 & & \\
\hline & 26 & 18 & & \\
\hline Comfort of working environment & $2.00(1.00-3.75)$ & $5.00(4.00-5.00)$ & $Z=-5.449$ & $<0.001$ \\
\hline Self-perceived security & $4.00(3.00-5.00)$ & $5.00(4.00-5.00)$ & $Z=-2.123$ & 0.034 \\
\hline The convenience of information system & $3.00(3.00-4.00)$ & $4.00(4.00-4.00)$ & $Z=-3.256$ & 0.001 \\
\hline Operational process flexibility & $0.00(0.00-1.00)$ & $3.00(2.00-4.00)$ & $Z=-2.601$ & 0.009 \\
\hline Pharyngeal acquisition visibility & $4.00(3.00-4.00)$ & $4.00(4.00-4.00)$ & $Z=-1.651$ & 0.099 \\
\hline Effectiveness of communication & $3.00(3.00-4.00)$ & $4.00(4.00-5.00)$ & $Z=-3.177$ & 0.001 \\
\hline
\end{tabular}

\section{RESULTS}

We received 60 valid responses from the nurses. The effective recovery rate was $100.00 \%$. Three hundred valid questionnaires were collected from the people comprising the sample. The effective recovery rate was $100 \%$.

\section{Comparison of Satisfaction Scores Between the Two Groups of Nurses With Different Throat Swab Collection Working Modes}

The two nursing staff groups had no statistically significant differences in basic characteristics of demography, which included working years, age, professional title, and educational background $(P>0.05)$, which means they were baseline comparable. The comfort of the nursing staff using the collection booth, selfperceived security, the convenience of the information system, the flexibility of the operation process, and the effectiveness of nurse-patient communication were statistically significant between the two groups of nurses (Table 1).

According to the results of bivariate and multivariate analysis, utilization of a mobile multifunctional workstation for coronavirus nasopharyngeal/oropharyngeal specimen collection can significantly improve the comfort of the working environment $(\mathrm{OR}=17.29795 \%$ CI: 4.294, 69.673), the convenience of information systems $(\mathrm{OR}=6.25095 \%$ CI: 1.775, 22.008), and effectiveness of communication $(\mathrm{OR}=5.58895 \%$ CI: 1.590, 19.646). Age, years of work, positional titles, educational degree, and method of coronavirus nasopharyngeal/oropharyngeal specimen collection had no statistically significant effect on operational process flexibility $(P$ $>0.05)$. We got the same result on self-perceived security and pharyngeal acquisition visibility (Tables 2, 3).

\section{Comparison of Satisfaction Scores Between the Two Groups Among Individuals Who Were Collected Throat Specimens Before and After Using the Collection Kiosk}

There were no statistically significant differences in terms of sex, age, and educational level between the two groups $(P>0.05)$, which means they were comparable. The scores of self-perceived safety and overall satisfaction during the observation group's throat swab sampling process were higher than those of the control group, and the difference $(P<0.05)$ was statistically significant (Table 4).

\section{DISCUSSION}

The convenience of the information system of the observation group among nurses is 6.25 times that of the control group. A significant innovation of the current work is that an information system was installed into the workstation. The kiosk supports the scanning and registering sampling of test tubes and can realize information registration and transmission through mainstream barcodes/two-dimensional codes. After scanning, data will be uploaded automatically, and the staff can view the sample information through the medical system. The information system reduces the burden of nurses in terms of writing and improves the comfort of use. It is convenient for data maintenance, unified management, and traceability. Reducing the workload is conducive to nurses undertaking more sampling work. Simultaneously, it also grants the medical system a greater sampling capacity, which is of significance for epidemic prevention and control.

During the collection of nucleic acid, wearing N95 masks and goggles for a long time causes facial indentation, dermatitis, acne, 
TABLE 2 | Bivariate and multivariate analysis of comfort of working environment.

\begin{tabular}{|c|c|c|c|c|}
\hline & $\begin{array}{l}\text { Unadjusted odds ratio } \\
(95 \% \mathrm{Cl})\end{array}$ & $P$-value & $\begin{array}{l}\text { Adjusted odds ratio } \\
\text { (95\% Cl) }\end{array}$ & $P$-value \\
\hline \multicolumn{5}{|l|}{ Age } \\
\hline $18-29$ & Ref. & 0.287 & $0.366(0.072,1.855)$ & 0.225 \\
\hline 30-39 & $4.200(0.698,25.264)$ & 0.117 & & \\
\hline$\geq 40$ & $1.213(0.404,3.645)$ & 0.730 & & \\
\hline \multicolumn{5}{|l|}{ Years of work } \\
\hline$\leq 10$ & Ref. & 0.420 & $1.251(0.305,5.130)$ & 0.756 \\
\hline $10-20$ & $1.833(0.472,7.216)$ & 0.382 & & \\
\hline$\geq 21$ & $2.333(0.655,8.309)$ & 0.191 & & \\
\hline \multicolumn{5}{|l|}{ Positional titles } \\
\hline Primary nurses & Ref. & & & \\
\hline Supervisor and deputy chief nurse & $1.125(0.405,3.126)$ & 0.821 & & \\
\hline \multicolumn{5}{|l|}{ Educational degree } \\
\hline Junior college education & Ref. & & & \\
\hline Bachelor degree or above & $0.754(0.220,2.585)$ & 0.654 & & \\
\hline \multicolumn{5}{|c|}{ Method of coronavirus nasopharyngeal/oropharyngeal specimen collection } \\
\hline PPE & Ref. & & & \\
\hline Workstations & $15.000(4.039,55.708)$ & $<0.001$ & $17.297(4.294,69.673)$ & $<0.001$ \\
\hline
\end{tabular}

TABLE 3 | Bivariate and multivariate analysis of the convenience of information system and effectiveness of communication.

\begin{tabular}{|c|c|c|c|c|}
\hline & $\begin{array}{l}\text { Unadjusted odds ratio } \\
\qquad(95 \% \mathrm{Cl})\end{array}$ & $P$-value & $\begin{array}{l}\text { Unadjusted odds ratio } \\
(95 \% \mathrm{Cl})\end{array}$ & $P$-value \\
\hline \multicolumn{5}{|l|}{ Age } \\
\hline $18-29$ & Ref. & 0.502 & Ref. & 0.449 \\
\hline 30-39 & $0.846(0.171,4.198)$ & 0.838 & $1.500(0.245,9.179)$ & 0.661 \\
\hline \multicolumn{5}{|l|}{ Years of work } \\
\hline$\leq 10$ & Ref. & 0.561 & Ref. & 0.636 \\
\hline $10-20$ & $1.111(0.294,4.205)$ & 0.877 & $0.655(0.160,2.680)$ & 0.556 \\
\hline$\geq 21$ & $1.889(0.530,6.727)$ & 0.326 & $0.530(0.143,1.962)$ & 0.342 \\
\hline \multicolumn{5}{|l|}{ Positional titles } \\
\hline Primary nurses & Ref. & & Ref. & \\
\hline Bachelor degree or above & $1.381(0.400,4.767)$ & 0.610 & $0.655(0.176,2.437)$ & 0.528 \\
\hline \multicolumn{5}{|c|}{ Method of coronavirus nasopharyngeal/oropharyngeal specimen collection } \\
\hline PPE & Ref. & & Ref. & \\
\hline Workstations & $6.250(1.775,22.008)$ & 0.004 & $5.588(1.590,19.646)$ & 0.007 \\
\hline
\end{tabular}

and itching (5-8). High mental pressure, being unaccustomed to and uncomfortable wearing PPE, and inconvenient movement all affect the clarity of vision, operating sensitivity, and accuracy (9-11). Especially during summer, wearing PPE for a long time causes physical exhaustion among medical staff. A series of manifestations such as insufficient blood and oxygen supply, and being prone to collapse and heatstroke further increase the difficulty and intensity of the work of nasopharyngeal swab collection (12). Further, during winter, the low temperatures prevent nurses from collecting samples outdoors for a long time. Thus, nurses are dissatisfied with the working environment.

To make the nurses more comfortable, the collection kiosk adopts a fully enclosed state with built-in air conditioning, which 
TABLE 4 | Comparison between two groups of people requiring nasopharyngeal swabs.

\begin{tabular}{|c|c|c|c|c|}
\hline Group & $\begin{array}{l}\text { Control group } \\
(n=150)\end{array}$ & $\begin{array}{l}\text { Observation group } \\
\qquad(n=150)\end{array}$ & $Z$-value & $P$-value \\
\hline Sex & & & 2.940 & 0.086 \\
\hline Male & 107 & 93 & & \\
\hline Female & 43 & 57 & & \\
\hline Age & $43.00(31.50-52.00)$ & $41.00(30.00-51.00)$ & -0.178 & 0.858 \\
\hline Education degree & $3.50(1.75-3.00)$ & $3.00(2.00-3.00)$ & -0.682 & 0.495 \\
\hline Self-perceived security & $2.00(1.75-3.00)$ & $2.00(2.00-3.00)$ & -1.965 & 0.049 \\
\hline Waiting time & $3.50(2.00-4.00)$ & $3.00(2.25-4.00)$ & -0.063 & 0.950 \\
\hline Overall satisfaction & $3.00(2.00-3.00)$ & $3.00(2.00-4.00)$ & -2.053 & 0.040 \\
\hline
\end{tabular}

can prevent infection by the stable positive pressure control, and a 99\% HEPA clean filter device (13). This design reduces the necessitation of using PPE. The comfort of the working environment of the observation group among nurses is 15.00 times that of the control group. It ensures that nurses are energetic and not overburdened, which provides a guarantee for long-term nucleic acid sampling and is of significance to the normalization of epidemic prevention and control.

Moreover, improving the comfort of nurses' working environment may positively affect nurses' negative emotions because some studies have shown that nurses' negative emotions, such as anxiety, are related to job dissatisfaction (14). The high prevalence of emotional distress in medical staff during the COVID-19 pandemic deserves great attention (15-19). Nurses are more prone to anxiety in the late stage of epidemic development (20-22). The relationship between the negative emotions and the comfort of the working environment is worthy of further study in the future.

Protective equipment that satisfies the protective standard usually affects the sense of hearing, which can lead to difficulties in communication between nurses and patients taking the nucleic acid tests. This collection booth has a voice interaction system to solve this problem. The satisfaction with communication among nurses in the observation group was 5.59 times that of the control group.

In the process of application, we found another advantage of the multi-functional workstation compared with the traditional PPE. The multi-functional workstation is more environmentallyfriendly. Some components of personal protective equipment are produced from non-renewable fossil resources. The process of mass production of PPE will also lead to large consumption of fossil fuels (23). Because of the poor recyclability of these plastic compounds (24), improper treatment can cause plastic pollution $(25,26)$, thus affecting the ecological environment of the sea and soil $(24,27,28)$. In addition, the virus remaining on PPE needs to be properly disinfected, otherwise, it may cause virus transmission.

The author believes that the sampling field of view of medical staff is significantly reduced under the third-level protection standard. The head-mounted LED light can help see the sampling location better, reduce the sampling time, and improve sampling accuracy. The $P$-value of the pharyngeal acquisition visibility referred to 0.088 , which was between 0.05 and 0.1 . It may be related to the small sample size, which needs to be expanded in the future.

The overall satisfaction and the self-perception security of the observation group among people who took nuclear acid tests were statistically different from those of the control group, which means utilization of a mobile multifunctional workstation can help to reduce people's anxiety. Those who have close contact with confirmed cases of the new COVID-19 should be tested for nucleic acid. Improving satisfaction with nucleic acid and reducing anxiety is conducive to people's cooperation in epidemic prevention and control.

Besides, we put the induction dustbin, hand disinfectant, and pharyngeal swab in the sink to expand the space and improve the operational process flexibility. But the results showed that the self-perceived security and operational process flexibility were not statistically significant between the two groups among nurses, which suggests that we should further optimize the design. In addition, sampling waiting times were not statistically significant between the two groups among people involved in throat specimen collection. It may be because that waiting time is affected by many factors such as the degree of cooperation and age of the sampled individuals. The results require further expansion of the sample size for demonstration.

One limitation of this study was that the sample size was small, so the conclusions should be treated with caution. However, through the research above, it has been preliminarily confirmed that a multifunctional collection kiosk can improve the comfort of nurses. In the future, we can further expand the sample size and conduct research across a wider range to further confirm the conclusions of this paper. Another limitation is that the nucleic acid results of the participants in our study are negative, and we cannot objectively compare the safety of the two methods. More research in this area is needed in the future.

Recently, there have been frequent outbreaks of new and severe infectious diseases worldwide, which have caused great harm to human health, such as severe acute respiratory syndrome, Ebola virus, and so on. When medical staff come into contact with such patients, they are often exposed to contaminated blood, body fluids, or aerosol environments, and the risks they face are becoming increasingly severe (29). This collection kiosk provides a safe, comfortable, convenient, 
efficient, and flexible working mode for medical staff. The mobile multifunctional sample collection workstation has a simple operation, which alleviates the working pressure of nurses to a certain extent, creates a comfortable and safe sampling environment for nurses and people providing the samples, and improves the overall satisfaction of both parties.

\section{DATA AVAILABILITY STATEMENT}

The raw data supporting the conclusions of this article will be made available by the authors, without undue reservation.

\section{ETHICS STATEMENT}

The Declaration of Helsinki conducted the study. All the participants signed informed consent. The studies involving human participants were reviewed and approved by the Ethics Committee of Beijing Youan Hospital Affiliated to Capital Medical University.

\section{REFERENCES}

1. National Health Commission. Covid-19 Diagnosis and Treatment Plan (Trial Version 8). (2021). Available online at: http://www.gov.cn/zhengce/ zhengceku/2021--04/15/content_5599795.htm (accessed April 25, 2021).

2. Liu A, Li M, Zhou Q, Ai J, Zheng W, Zeng XJ, et al. Value of swab types and collection time on sars-cov-2 detection using rt-pcr assay. J Virol Method. (2020) 286:113974. doi: 10.1016/j.jviromet.2020.113974

3. National Health Commission. Notice of the General Office of the National Health Commission on Issuing the Guidelines for the Use of Common Medical Protective Products in the Prevention and Control of Pneumonia Caused by Covid-19 Infection. (2021). Available online at: http://www.gov. cn/zhengce/zhengceku/2020--02/05/content_5474688.htm (accessed April 25, 2021).

4. National Health Commission. Notice of the General Office of the National Health Commission on Printing and Distributing the Pneumonia Prevention and Control Plan of Covid-19. 3rd ed. (2021). Available online at: http://www. gov.cn/zhengce/zhengceku/2020--02/22/content_5482010.htm (accessed April 25, 2021).

5. Montero-Vilchez T, Cuenca-Barrales C, Martinez-Lopez A, Molina-Leyva A, Arias-Santiago S. Skin adverse events related to personal protective equipment: a systematic review and meta-analysis. J Eur Acad Dermatol Venereol. (2021) 35:1994-2006. doi: 10.1111/jdv.17436

6. Etgu F, Onder S. Skin problems related to personal protective equipment among healthcare workers during the covid-19 pandemic (online research). Cutaneous Ocular Toxicol. (2021) 40:207-13. doi: 10.1080/15569527.2021.1902340

7. Park SJ, Han HS, Shin SH, Yoo KH, Li K, Kim BJ, et al. Adverse skin reactions due to use of face masks: a prospective survey during the covid19 pandemic in korea. J Eur Acad Dermatol Venereol. (2021) 35:e628-30. doi: $10.1111 /$ jdv.17447

8. Yaqoob S, Saleem A, Jarullah FA, Asif A, Essar MY, Emad S. Association of acne with face mask in healthcare workers amidst the covid-19 outbreak in karachi, pakistan. Clin Cosmetic Investig Dermatol. (2021) 14:1427-33. doi: 10.2147/CCID.S333221

9. Rizzi A, Inchingolo R, Viola M, Boldrini L, Lenkowicz J, Lohmeyer FM, et al. Occupational hand dermatitis web survey in a university hospital during covid-19 pandemic: the shield study. La Medicina del Lavoro. (2021) 112:320-6. doi: 10.23749/mdl.v112i4.11670

10. Makowiec-Dabrowska T, Gadzicka E, Bortkiewicz A. Physiological cost of wearing protective masks - a narrative review of the literature. Medycyna Pracy. (2021) 72:569-89. doi: 10.13075/mp.5893. 01107

\section{AUTHOR CONTRIBUTIONS}

HG and LZ contributed to the design of this study. JM, YL, XJ, $\mathrm{XLiu}, \mathrm{JH}$, and YZhan contributed to data collection. YZhao and XLia analyzed the data and wrote the article. All authors have read and approved the final manuscript.

\section{FUNDING}

This work was supported by the Major Project of Beijing Municipal Science and Technology Committee (No. Z201100005520063), National Science and Technology Major Project of China during the 13th Five-Year Plan Period (No.2017ZX10201101), Beijing Excellent Talent Plan (No. 2018000021223ZK04), Beijing Talent Project in the New Millennium (No. 2020A35), and Beijing Hospitals Authority Clinical medicine Development of special funding support (No. XMLX202147).

11. Marraha F, Al Faker I, Charif F, Chahoub H, Benyamna Y, Rahmani N, et al. Skin reactions to personal protective equipment among first-line covid19 healthcare workers: a survey in northern morocco. Ann Work Exposures Health. (2021) 65:998-1003. doi: 10.1093/annweh/wxab018

12. Liuyi Li YG, Gong Y. The necessity and significance of "hospital isolation technical standards." Chinese Nurs Manag. (2009) 9:5-6.

13. Coca A, Quinn T, Kim JH, Wu T, Powell J, Roberge R, et al. Physiological evaluation of personal protective ensembles recommended for use in west africa. Disast Med Public Health Preparedn. (2017) 11:580-6. doi: $10.1017 / \mathrm{dmp} .2017 .13$

14. Da Rosa P, Brown R, Pravecek B, Carotta C, Garcia AS, Carson P, et al. Factors associated with nurses emotional distress during the covid-19 pandemic. Appl Nurs Res. (2021) 62:151502. doi: 10.1016/j.apnr.2021.151502

15. Tao M. Psychological protection of front-line medical staff and related staff during the covid-19. Zhejiang Clin Med. (2020) 22:194-97.

16. Tan F, Sheng L, Zhang R, Wu Q, Lan X. A mixed study on anxiety of front-line medical staff during the outbreak of covid-19. J Nurs. (2020) 35:82-3.

17. Mana TSC, Tomas ME, Cadnum JL, Jencson AL, Piedrahita CT, Donskey CJ. A randomized trial of two cover gowns comparing contamination of healthcare personnel during removal of personal protective equipmentInfection control and hospital. Epidemiology. (2018) 39:97-100. doi: 10.1017/ice.2017.249

18. Xu X, Wang W, Chen J, Ai M, Shi L, Wang L, et al. Suicidal and self-harm ideation among chinese hospital staff during the covid-19 pandemic: prevalence and correlates. Psychiatry Res. (2021) 296:113654. doi: 10.1016/j.psychres.2020.113654

19. Gilbert GL. Australia's response to ebola virus disease in west africa, 2014-15. Public Health Res Practice. (2016) 26:51661. doi: 10.17061/phrp26 51661

20. Chen G, Gong J, Qi Z, Zhong S, Su T, Wang, J, et al. The psychological status of general population in hubei province during the covid-19 outbreak: A cross-sectional survey study. Front Public Health. (2021) 9:622762. doi: 10.3389/fpubh.2021.622762

21. Xiaoming X, Ming A, Su H, Wo W, Jianmei C, Qi Z, et al. The psychological status of 8,817 hospital workers during covid-19 epidemic: a cross-sectional study in chongqing. J Affect Disord. (2020) 276:555-61. doi: 10.1016/j.jad.2020.07.092

22. Lixia W, Xiaoming X, Lei S, Su H, Wo W, Xin, F, et al. A crosssectional study of the psychological status of 33,706 hospital workers at the late stage of the covid-19 outbreak. J Affect Disord. (2021) 297:156-68. doi: 10.1016/j.jad.2021.10.013

23. Zhao X, Jaromír Klemeš J, You F. Energy and environmental sustainability of waste personal protective equipment (ppe) treatment under covid-19. 
Renew Sustain Energy Rev. (2021) 153:111786. doi: 10.1016/j.rser.2021. 111786

24. Vanapalli KR, Sharma HB, Ranjan VP, Samal B, Bhattacharya J, Dubey $\mathrm{BK}$, et al. Challenges and strategies for effective plastic waste management during and post covid-19 pandemic. Sci Total Environ. (2021) 750:141514. doi: 10.1016/j.scitotenv.2020.141514

25. Jaromír Klemeš J, Van Fan Y, Tan RR, Jiang P. Minimising the present and future plastic waste, energy and environmental footprints related to covid19. Renew Sustain Energy Rev. (2020) 127:109883. doi: 10.1016/j.rser.2020. 109883

26. You S, Sonne C, Ok YS. Covid-19's unsustainable waste management. Science. (2020) 368:1438. doi: 10.1126/science. abc7778

27. Fadare OO, Okoffo ED. Covid-19 face masks: a potential source of microplastic fibers in the environment. Sci Tot Environ. (2020) 737:140279. doi: 10.1016/j.scitotenv.2020.140279

28. Mohammad A, Goli V, Singh DN. Discussion on 'challenges, opportunities, and innovations for effective solid waste management during and post covid-19 pandemic. Resour Conserv Recycl. (2021) 164:105175. doi: 10.1016/j.resconrec.2020.105175

29. Verbeek JH, Rajamaki B, Ijaz S, Sauni R, Toomey E, Blackwood B, et al. Personal protective equipment for preventing highly infectious diseases due to exposure to contaminated body fluids in healthcare staff. Cochr Database Systemat Rev. (2020) 5:Cd011621. doi: 10.1002/14651858.CD011621.pub5

Conflict of Interest: The authors declare that the research was conducted in the absence of any commercial or financial relationships that could be construed as a potential conflict of interest.

Publisher's Note: All claims expressed in this article are solely those of the authors and do not necessarily represent those of their affiliated organizations, or those of the publisher, the editors and the reviewers. Any product that may be evaluated in this article, or claim that may be made by its manufacturer, is not guaranteed or endorsed by the publisher.

Copyright (c) 2022 Lian, Zhang, Zhao, Li, Jing, Liu, Han, Ma, Zhang, Guo and Huang. This is an open-access article distributed under the terms of the Creative Commons Attribution License (CC BY). The use, distribution or reproduction in other forums is permitted, provided the original author(s) and the copyright owner(s) are credited and that the original publication in this journal is cited, in accordance with accepted academic practice. No use, distribution or reproduction is permitted which does not comply with these terms. 